\title{
The relation between organizational commitment and managerial effectiveness of instructors at schools of physical education and sports
}

\author{
Eyup DALKIRAN 1 , Erkan Faruk SIRIN² \\ ${ }^{1}$ General Police Directorate, Police, Turkey. \\ ${ }^{2}$ Faculty of Sport Sciences, Department of Sports Management, Selcuk University, Konya, Turkey. \\ The paper presented orally at the $1^{\text {th }}$ International Management Research Congress (19-20 March 2016), Ankara, Turkey. \\ Address correspondence to E. F. Sirin, e-mail; erkanfaruk@yahoo.com
}

\begin{abstract}
The aim of this study is to verify whether there is a relation between managerial effectiveness and organizational commitments of the instructors who work at SPES (School of Physical Education and Sports) that are considered as organizations. The study was carried out with a group of 232 instructors voluntarily participating in the research from 29 SPES. The research data were collected through "Personal Information Form", "Organizational Commitment Scale" and "Managerial Effectiveness Scale". In the study, data were analyzed with descriptive statistical procedures such as frequency, percentage, arithmetic mean, standard deviation and correlation. At the end of the research, it was observed that the instructors generally have a strong commitment to their organizations and that they perceived their administrators' managerial effectiveness as "partially agree", the perception of the sense of managerial effectiveness of their administrators is medium. It was identified that there is a positive correlation between emotional commitment extent of organizational commitment scale and all sub-extents of managerial effectiveness; low positive correlation between the continuation dimensions of the organization; and there is a medium level of the positive correlation between the normative extent of organizational commitment and all sub-extents of managerial effectiveness.
\end{abstract}

Keywords: Managerial effectiveness, organizational commitment, academic staff, school of physical education and sports.

\section{INTRODUCTION}

Although there are adequate number of studies on managerial effectiveness for industrial institutions, there are almost no researches for higher education. For this reason, a gap is naturally observed to identify efficiencies of the individuals who have academically managerial efficiencies. Hence, the effectiveness of the managers is highly related with how the management provides with the efficiency on their basic functions. Management, managers and their concept of organizational commitment is among the factors that directly affect the variables in relation with the organization (24). Benkhoff (9) stated in his research that employees who think of their managers as competitive, trustworthy, active and have positive managerial attitude, considerably share the organizational values and are proud to be a member of the organization they belong to.
In line with general aims of the Turkish National Education, as it is the responsibility of primary and secondary education institutions, Physical Education teacher training, General Directorate of Sports (GDS) provides trainers, managers training in various branches to the central and provincial organizations and sports clubs, as well as the role of leading cultivation in private sector that can function in a wide range of fields (tourism, industry, municipalities, etc.) it is vital for the instructors who work at schools of Physical education and Sports to have organizational commitment and managerial effectiveness.

Various factors affect organizational commitment levels of the instructors working at universities. These factors, to be for the advantage of the employees, contributes both the workers and the institution. Individuals' increased sense of belonging to the institution leads to the development of security sentiment. Refusing career advancement 
and job change opportunities by feeling that individuals can be useful for their organization provides a decent workforce that reassures the organization. These employees, who obtain determined and confidential workforce, can easily adopt the aims of the organization. An increase in their productivity, increases the quality of the education and this is provided by the effective communication within the organization and with the commitment the employees have through the organization (18).

At this point, "organizational commitment is described with the perspective of the level of the employees to adopt the values and the goals of the organization and an emotional commitment to the organization" (31), "the behavior to stay within the organization" $(2,29,30)$. There are a number of conditions to consider for work conditions in order to increase organizational commitment. Basically, positive perceptions about managerial effectiveness contributes to the organizational commitment.

While higher education organizations are taking place in an environment getting more complicated day by day, higher education managers are being stuck by the decrease in the funds and money issues, demands for new programs and change. Besides, there occurs some obligations for formal procedures (33). All these formations take the concept of managerial effectiveness to a higher position. Managerial effectiveness is provided by the managerial functions like planning, supervision, decision-making, communication and leadership (12). Kowalski (27) within the academic environment, describes educational managers with some responsibilities such as representing the organization, organization, leadership, management, facilitation, peacemaking and communication. Evaluation of the effectiveness in managerial functions contributes to the organization to be managed effectively. Evaluation of the managerial effectiveness in higher education through managerial functions makes it possible to reach the goals that were formerly decided.

Academic managers, who undertake management duty, are responsible for reaching the goals specified beforehand and providing with human and item supplies needed. In this process, besides their legal powers, they need to have social, technical, cultural, and charismatic powers (7). The features that the effective leaders are demanded to have are; persuasion, making positive impact, correct communication skills, being positive role model and balance of responsibility (20). Furthermore, it is an obligation that an academic manager to have the quality to serve in his branch in order to monitor his co-instructors (4). In other words, academic managers, primarily need to know and derive from the discipline that they are administrating in. It is open to debate whether the managers, especially who are not very competent on the goals and the education system of the school they are administrating successfully executing the management process or not. For example, with the absence of instructors from Physical Education \& Sports department or for some other reasons, especially in state universities, managers from Faculty of Agriculture, Faculty of Veterinary science or medical faculty come to power in schools of Physical Education \& Sports, which brings about lots of problems.

For the universities whose scope is to "raise human beings" as well as producing scientific information to act for their goals, instructors are needed to fulfill their responsibilities and duties. It can be stated that for the instructors to perform their roles at the universities, the social and economic opportunities that the organization provides with the relations built within the organization, working schedule, academic title and sense of commitment the instructors have as well as their mental potentials, cognitive and personal features will contribute to their productivity.

When literature is studied in Turkey, no researches will be encountered on organizational commitment and managerial effectiveness of schools of physical education and sports. This research, may contribute to identify the feature of organizational commitment and managerial effectiveness at the schools of Physical Education and Sports from the perspective of the instructors, and to understand managerial effectiveness of the schools.

The aim of this study is to examine the relationship between managerial effectiveness and organizational commitments of the instructions serving in SPESs of the universities. In order to realize the objectives of the research, the question: "Is there a meaningful relationship between the managerial effectiveness and organizational commitment perceptions of the instructors participating in the research?" was tried to be answered. 


\section{MATERIALS \& METHODS}

\section{Research Model}

This study, which aims to investigate the relationship between academic staff's perceptions of managerial effectiveness and organizational commitment, is a research in descriptive-relational screening model.

\section{Population and Sample}

The universe of the research consists of instructors, lecturers, experts and research assistants serving at 52 schools of Physical Education \& Sports (SPES) connected to state universities by the 20112012 academic year, and 3 Sports Sciences \& Technologies Colleges (SSTC) (34). Data of the research were gathered through survey forms and online survey. In the process of research, it was thought that the best way to reach the instructors would be the internet. Thus, e-mail addresses of the instructors were tried to be gathered from the internet sites of the universities and a list of 1120 email addresses were made in total (16). In this context, the universe of the research consists of email addresses of 1120 instructors. 1120 instructors were invited to attend the online survey. At the end of this process, instructors serving in 27 school of physical education and $\operatorname{sports}(\mathrm{n}=221)$ and 2 Sports Sciences \& Technologies college $(\mathrm{n}=11)$ were identified to attend the research. In this way, the sampling group of the research consists of 232 instructors [associate professor $(\mathrm{n}=16)$, assistant professor $(\mathrm{n}=77)$, instructor( $(\mathrm{n}=56)$, lecturer $(\mathrm{n}=26)$, research assistant $(\mathrm{n}=57)]$.

\section{Data Collecting Instruments}

A data collection tool that consists of 3 parts were used to gather data in order to identify the relationship between the sense of organizational commitment and managerial effectiveness of the instructors attending the survey. For this aim, primarily domestic and foreign researches were analyzed. In the first part of the research, the instructors were addressed questions aimed to identify the relationship between personal qualities and organizational commitment and managerial effectiveness. The questions regarding personal information were created by the researcher by making a literature review. In the second part, a distinctive form that consists of 18 entries of organizational commitment scale to evaluate organizational commitment. The expressions in the scale are in the form of five points Likert scale. Across each expression there are degrees of agreement level like; "I definitely disagree=1", "I disagree=2", "I moderately agree=3", "I mostly agree $=4 "$, "I totally agree $=5$ " (1). In the third part, in order to evaluate managerial effectiveness, a scale of 44 entries that were developed by Murry (32) and updated in 2009 and adjusted to Turkish by Ira \& Şahin (23).

The answer codes are listed from negative to positive 1.00- 5.00. Firstly, lower and upper limits were identified for the options. Then the ratings were gathered in three levels. These levels were stated in The Table.1 below as "I definitely agree", and "I mostly agree" to be "sufficient level"; "I partially agree" to be "mid level"; and "I disagree" and "I definitely disagree" to be "insufficient level".

\section{Data Analysis}

The distribution of organizational commitment and managerial effectiveness levels of the instructions were determined by calculating arithmetic means and standard deviations of the answers given scales. Then, we made use of correlation index analysis techniques to reveal the relationship between organizational commitment levels and managerial effectiveness levels of the instructors. In explication of the correlation index, it was agreed that the result $0.70-1.00$ is high; $0.70-0.30$ is moderate; and $0.30-0.00$ is low (10). In explication of the results 0.05 levels of meaningfulness level was taken as a base.

Table 1. Limits and score intervals related to organizational commitment and managerial effectiveness.

\begin{tabular}{llccc}
\hline Options & & Option Limits & Levels & Limits \\
\hline I definitely agree & $(5)$ & $4.20-5.00$ & Sufficient Level & $3.40-5.00$ \\
I mostly agree & $(4)$ & $3.40-4.19$ & Mid-Level & $2.60-3.39$ \\
I partially agree & $(3)$ & $2.60-3.39$ & & \\
I disagree & $(2)$ & $1.80-2.59$ & Insufficient Level & $1.00-2.59$ \\
I definitely disagree & $(1)$ & $1.00-1.79$ & & \\
\hline
\end{tabular}




\section{RESULTS}

Results related to personal features of the participants

$29.3 \%$ of the participants are female, and 70.7 are male. Distribution of the participants according to age variable is as; $22 \%$ 31-35 years old, $19 \% 36-40$, $16.8 \% 26-30,14.2 \%$ 41-45, $12.9 \% 46-50,10.8 \% 51$ and over, $4.3 \% 24$ and under. According to the variable of the departments of the instructors, the distribution is as follows; $37.1 \%$ schools of Physical Education and Sports, 24.6 \%Trainers' Education Department, $23.7 \%$ Managers of Sports Departments, $14.7 \%$ Recreation Department. The distribution according to their title is as follows; $33.2 \%$ assistant professor, $24.6 \%$ research assistant, $24.1 \%$ instructor, $11,2 \%$ lecturer and $6.9 \%$ associate professor. According to the variable of seniority, the distribution is as follows; $23.7 \% 16-20$ years, $22.8 \% 1$ 5 years, $19.8 \% 11-15$ years, $18.5 \%$ 6-10 years, $8.2 \% 26$ years and over, $6.9 \% 21-25$ years. According to the variable of instructors, being on an administrative function, it was observed that the $78 \%$ of the participants did not have any administrative functions (principals, assistant principals, head of a department, chief of a department, assistant chief of a department) and $22.0 \%$ had administrative functions.

\section{Results related to organizational commitment and managerial effectiveness levels}

Findings on sub-dimensions of organizational commitment \& managerial effectiveness levels of the participants are stated in Table 2.

The arithmetic mean of emotional commitment dimension of organizational commitment of the instructors is $3.80 \pm 0.70$; arithmetic mean of continuation commitment dimension is $3.36 \pm 0.59$ and arithmetic mean of the normative commitment dimension is $3.13 \pm 0.83$. According to the findings in the table, it can be said that the instructors who attended the survey generally have adequate level of commitment through their institution and that their "continuation commitment" and "normative commitment" is in mid-level.

The arithmetic mean of planning $\mathcal{E}$ deciding dimension of managerial effectiveness scale of instructors is $2.91 \pm 0.93$; arithmetic mean of organizing and the management of human resources dimension is; $3.01 \pm 0.95$; arithmetic mean of the group study dimension is $3.12 \pm 0.91$; arithmetic mean of the communication dimension is $3.38 \pm 0.99$; arithmetic mean of the leadership dimension is $3.31 \pm$ 1.03. According to the findings in the list, it is stated that managerial effectiveness levels of the instructors with administrative functions like "planning \& deciding", "organizing and the management of human resources", "group study" and "communication" are moderate.

Results related to the correlation between the senses of organizational commitment \& managerial effectiveness of the participants

In order to identify whether there is a meaningful relationship between the senses of organizational commitment \& managerial effectiveness, correlation technique was used. The relationship between the senses of organizational commitment and managerial effectiveness of the participants are listed in Table 3.

Table 2. Related to organizational commitment and managerial effectiveness levels.

\begin{tabular}{lccc}
\hline Variables & $\mathrm{n}$ & Mean & $\mathrm{SD}$ \\
\hline Organizational Commitment & & & \\
Emotional Commitment & 232 & 3.80 & 0.70 \\
Continuation Commitment & 232 & 3.36 & 0.59 \\
Normative Commitment & 232 & 3.13 & 0.83 \\
Managerial Effectiveness & & & \\
Planning \& Deciding & 232 & 2.91 & 0.93 \\
Organizing and the Management of the Resources & 232 & 3.01 & 0.95 \\
Group Study & 232 & 3.12 & 0.91 \\
Communication & 232 & 3.38 & 0.99 \\
Leadership & 232 & 3.31 & 1.03 \\
\hline
\end{tabular}


Table 3. Relationship between the senses of organizational commitment \& managerial effectiveness.

\begin{tabular}{|c|c|c|c|c|c|c|c|}
\hline \multirow{8}{*}{ 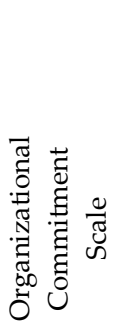 } & & & \multicolumn{5}{|c|}{ Managerial Effectiveness Scale } \\
\hline & & & $\begin{array}{l}\text { Planning and } \\
\text { Deciding }\end{array}$ & $\begin{array}{c}\text { Organizing and the } \\
\text { Management of the Resources }\end{array}$ & $\begin{array}{l}\text { Group } \\
\text { Study }\end{array}$ & Communication & Leadership \\
\hline & Emotional & $\mathrm{r}$ & $0.395^{* *}$ & $0.369^{* *}$ & $0.525^{* *}$ & $0.501^{* *}$ & $0.446^{* *}$ \\
\hline & Commitment & $\mathrm{p}$ & 0.000 & 0.000 & 0.000 & 0.000 & 0.000 \\
\hline & Continuation & $\mathrm{r}$ & 0.078 & 0.002 & $0.185^{* *}$ & $0.134^{*}$ & 0.078 \\
\hline & Commitment & $\mathrm{p}$ & 0.239 & 0.975 & 0.005 & 0.042 & 0.237 \\
\hline & Normative & $\mathrm{r}$ & $0.573^{* *}$ & $0.572^{* *}$ & $0.479^{* *}$ & $0.473^{* *}$ & $0.447^{* *}$ \\
\hline & Commitment & $\mathrm{p}$ & 0.000 & 0.000 & 0.000 & 0.000 & 0.000 \\
\hline
\end{tabular}

It was stated that there is a mid level of positive correlation between emotional commitment dimension of organizational commitment and planning and deciding $(\mathrm{r}=0.395 ; \mathrm{p}<0.01)$, organizing $\&$ the management of the resources $(\mathrm{r}=0.369 ; \mathrm{p}<0.01)$, group study $(\mathrm{r}=0.552 ; \mathrm{p}<0.01)$, communication $(\mathrm{r}=0.501$; $\mathrm{p}<0.01)$, leadership $(\mathrm{r}=0.446 ; \mathrm{p}<0.01)$; dimension of the managerial effectiveness scale, a low level positive relationship between continuation commitment dimension of organizational commitment and group study $(\mathrm{r}=0.185 ; \mathrm{p}<0.01)$ and communication $(\mathrm{r}=0.134$; $\mathrm{p}<0.05)$; dimensions of managerial effectiveness scale, and there is mid level of positive correlation between normative commitment dimension of organizational commitment and planning and deciding $(\mathrm{r}=0.573 ; \mathrm{p}<0.01)$, organizing $\&$ the management of the human resources $(\mathrm{r}=0.572 ; \mathrm{p}<0.01)$, group study $(\mathrm{r}=0.473 ; \mathrm{p}<0.01)$, communication $(\mathrm{r}=0.473$; $\mathrm{p}<0.01)$, and leadership $(\mathrm{r}=0.447 ; \mathrm{p}<0.01)$ dimensions of managerial effectiveness scale.

\section{DISCUSSION}

At the end of the research, it can be said that the instructors in general, are pleased with their institution, and that they consider themselves as a part of the organization (emotional commitment). One of the prominent conclusions of the research is that especially the SPES instructors have significantly high senses of emotional commitment. This can be an indicator of how these people are identified with their job. Emotional commitment is the kind of commitment most demanded by employers. The normative commitment that the employees feel responsible towards the organization; is not within the demanded level for the schools of physical education and sports members. In many researches on instructors, working at academic organizations $(3,11,13,17,18,28,34)$ it was stated that, while the emotional and normative commitments of the instructors were identified in demanded levels; their continuation commitments are in lower levels.
When we comment on the mid level of normative commitment levels of schools of Physical Education and Sports instructors, it is observed that these instructors are self-confident and that they feel they would be successful in other institutions, too. The high level of emotional commitment of the teaching staff in relation to their continuing and normative commitment is related to the satisfaction of employees in the organization and the existence of a sincere, cozy and peaceful working environment among themselves, including managers.

Looking at the least demanded type of commitment by the institutions, the cost accounting and continuation commitment based on the lack of business alternatives; instructions at Schools of Physical Education and Sports show moderate level of commitment. That is, if they leave the institution, and find another job in equal circumstances, they will not feel that the institution would owe much to them. Also, this may result from policies adopted at universities $_{\bar{T}}$ that there is no work assurance at positions lower than professor \& assistant professor. On the other hand, that the continuation commitment levels of the instructors working at universities is moderate can be interfered with the features of Wasti's "Collectivist Culture". Wasti (37), stated that Turkish employees may be feeling continuation commitment towards their institutions as they don't like changes, and he expressed that this may be related to the cultural dimension that Hofstede described as "avoidance of uncertainty", is in high level. "Avoidance of uncertainty is referred to people who do not like change. These kind of people prefer certainty in their lives and escape risks. In terms of uncertainty avoidance by Hofstede's work in Turkey, which is the 16th in the ranking of 53 countries (37), Turkey is considered to be a society that is so relative as to avoid uncertainty, which illustrates the level of commitment continues as cultural research findings. When the findings of the research is evaluated through organizations of universities in Turkey. It is 
a well-known fact that those who work at universities are under state security and there is scarcely any occasions of firing (especially except 50 /d staff). This context may explain the reason why the instructors working at universities have a mid level of continuation commitment.

Additionally, according to the findings, the instructors working at schools of Physical Education and Sports think that the administrators do not have sufficient level of managerial effectiveness.

When the managerial effectiveness dimensions are examined one by one, it is seen that the first dimension "Planning and Decision Making" subdimension is perceived by the instructors moderately. In the research carried out by Ira (21, 22) the instructors perceived the subject of administrators' providing with all kinds of help and encourage them to make efforts towards the goals of the organization, as "irresolute". Furthermore, in a research called "Managerial Problems at Higher Education" by Günal (19), it was concluded that instructors working at Educational Faculty, are aware of the problems of reaching the goals and they agree on tuition \& research facility in "mid level". These findings are parallel to the findings of this research. Besides, within the organizational structure of the higher education system, there is no regulation regarding preparing and providing information to the instructors about the budget of the organization (22). According to the perceptions of the instructors, it can be said that this process continues in the same way at the schools of Physical Education and Sports as well.

It is seen that the "organizational and human resources" sub-dimension is perceived by the instructors at a moderate level. In the research conducted by Günal (19), the most important problem perceived by the instructors was determined as the quality of teaching staff and democratization problem. In another study conducted by Al (1), the levels of "human management" and "supervision and evaluation" of managerial competence of foreign language units managers were found to be "moderate". In the research conducted by İra $(21,22)$, it was determined that "the instructors perceive in the range of" undecided "in the expression of" independent thinking and freedom of movement in working life". This supports the results of the research conducted.
It is seen that the "team work" sub-dimension is perceived moderately by the instructors. According to this conclusion, it can be said that there is not enough knowledge among the teaching staff in the Physical Education and Sports and accordingly, there is not enough consciousness to be a team. The research conducted by Bakan et al. (5) partially supports our findings in that there is good cooperation and co-operation among the teaching staff in the same department, but good cooperation and co-operation among the teaching staff in different departments is not sufficient. Moreover, in the research conducted by Ira (22), it is seen that the instructors' administrators perceive the level of "team work" as "partly agree". This supports the results of the research conducted.

The 'communication' dimension in which the perceptions of the instructors are determined at the highest level is again at moderate levels- It can be said that the instructors are able to research the administrators of the schools of Physical Education and Sports (Principals, assistant principals, head of departments and department assistants) but that they cannot express ideas in their talks. In a study by Al (1), the levels of communication of managerial competence of foreign language units, managers are set at mid level. In a research by İra (21). The instructors scored the range 'undecided' for the expression "The lecturers can express their thoughts about the university without hesitation." In another research by İra (22), it has been determined that instructors perceive the administrators' level of "communication" as "partially agree". In a study by Günal (19), it has been concluded that the problem of human relationships is more common in education faculties and medical faculties. In a research by Bakan et.al (5) it has been concluded that the vast majority of faculty members are always open to communication. They also stated that all communication channels are open in their faculties. These findings partially support the results of the research conducted.

It is seen that the instructors perceive the 'leadership' dimension at moderate level. According to these results, in line with the perceptions of the instructors, it can be said that this process is not at the desired level in the decision-making process of the managers in physical education and sport schools and they do not follow a participatory management mentality. In a study by Karslı (25), it was stated that the effectiveness measures the 
instructors demand from the managers are "face to face interaction" and "the effectiveness of the studies and the problem solving skills". In a similar way, in a study by Yukl (39), it was stated that strategic leadership has become increasingly important, human resources management and organizational change has been done on this subject. In a study carried out by Drew \& Bensley (15), It is stated that today, for the success of higher education organization individuals must lead, motivate and develop. In a research by Ira (22), it is seen that the administrators of the instructors perceive it as "partially agree" at the level of "leadership". This supports the results of the research conducted. In a research by Bakan et al. (5), it is stated that more than half of faculty members find faculty executives successful in their duties related to the institution. The results obtained from these studies partially support the conclusion of the study.

It was observed that the lecturers perceived all sub-dimensions of managerial effectiveness at moderate intervals. According to the perceptions of the instructors, "communication" is the highest level of managerial effectiveness. Furthermore, "leadership", "team work" and, "organization and human resources" come together. "Planning and decision making" is perceived at the lowest level. Regarding this conclusion, it can be commented that physical education and sports colleges are not managed effectively. This situation may prevent the organizational effectiveness and goals of the schools of physical education \& sports from being achieved at the desired level. Thus, the goal for educating qualified teachers, coaches \& administrators, which is the ultimate goal of these schools, cannot be achieved. The result of "Education Faculties research" that Turkish Council of Higher Education carried out in 2005 and the research by the Department of Educational sciences of the University of Ankara in 2005 show that academic boards are not totally functioning effectively in education faculties (40). In the study conducted by Günal (19), problems are perceived more intensely in education faculties than those of other faculties in terms of managerial qualities. In the research conducted by Bakan et al. (5), İra $(21,22)$, the instructors stated that the effect of senior management on the institutional functioning in general is excessive. The following result supports the findings of the research.
In the study of the relationship between organizational commitment sub-dimension levels and managerial effectiveness sub-dimension levels of researchers participating in the research, the following results were obtained:

It has been retained that there is a moderate positive relationship between "emotional commitment" of organizational commitment and " planning \& deciding", "organization \& human resources management", "teamwork", "communication" and "leadership" sub-dimension of managerial effectiveness. According to this result, it can be said that, when perceptions about the managerial effectiveness (planning \& deciding, organization \& the management of human resources, teamwork, communication and leadership) levels of the teaching staff working at the schools of physical education \&sports increases, the level of mental emotional commitment of the instructors will increase and when the perceptions of managerial effectiveness are low, the level of emotional commitment will decrease. In other words, it can be said that managers have positive instances on planning \& deciding, organization and the management of human resources, teamwork, communication, and leadership behaviors. It has been found that there is a low positive correlation between the level of "continuation commitment "of organizational commitment and "teamwork", "leadership" sub-dimension of managerial effectiveness. According to this result, it is thought that the desires of the instructors of SPES to say in institutions (continual commitment) may be associated with managerial co-operation with the instructors (teamwork), importance to their ideas and effective dialogue. That is, it is understood that the levels of managerial effectiveness and communication and teamwork dimensions may be at least partially effective in the continuing dimension of the organizational commitment of the instructors.

It has been found that there is a moderate positive relationship between perceptions of The level of "normative commitment" of organizational commitment and organizational and human resource management, planning and decision making, team work, communication and leadership sub-dimension levels of managerial effectiveness. According to this result, it can be said that the proficiency levels of all sub-dimensions of managerial efficacy of the schools of Physical 
Education and Sports affect positively the teachers' feelings of obligation to remain in the organization (normative commitment). Similar results have been achieved in studies on related topics conducted with different study groups, generally which in general sense, support our research findings $(6,8,14,35,36$, 38).

When the research is evaluated in general, in the researches by Kaya et al. (26) that support our findings, a positive and a high level of relationship has been determined between perceptions of administrative effectiveness and organizational commitment $(\mathrm{r}=.638)$, levels (of administrators and teachers working in primary and secondary schools. In a similar research by $\mathrm{Al}(1)$, it has been identified that there is a positive correlation in medium level between the managerial effectiveness and organizational commitment levels of the lecturers working at 14 universities consisting of eight state universities and six foundation universities. When the findings of the research were taken into consideration, that the level of organizational commitment levels of instructors working in schools of Physical Education and Sports' being high was influenced by the fact that their managerial effectiveness perceptions are at desired levels.

In order to determine the perceptions of organizational commitment and managerial effectiveness of the teaching staff working in schools of Physical Education and Sport and to determine whether there is a relationship between managerial effectiveness perceptions and organizational commitment, the following results were obtained in the research;

$>$ It has been determined that the lecturers' emotional commitments to their organizations are at a sufficient level and their normative and continuing commitments are moderate.

It has been established that there is a medium level of positive correlation between levels of "emotional commitment" of organizational commitment and "organizational and human resources management", "team work", "communication" and "leadership" sub-dimensions of managerial effectiveness; a low level of positive correlation between the level of "continuing commitment" of organizational commitment and "team work" and "leadership" sub-dimensions of managerial effectiveness; moderate positive correlation between the level of "normative commitment" of organizational commitment and "planning and decision making", "organization and human resources management", "team work", "communication" and "leadership" sub-dimensions of managerial effectiveness; moderate positive correlation between general organizational commitment levels and "organizational and human resources management", "team work", "communication" and "leadership" sub-dimensions of managerial effectiveness.

Considering the results of the research, the following suggestions can be made to the academic administrators who are working at the schools of Physical Education and Sports, establishing organizational commitment and ensuring managerial effectiveness;

$>$ One of the most important factors in increasing the contribution of the academic staff to their contributions is their commitment to their institution. Considered in this context, it has become important for academic managers to emphasize the level of commitment of their teaching staff to their institutions and thus to develop and implement human resource activities that will enable them to stay in the institution. While the academic administrators provide this, each commitment must be well understood and the instructors should be guided in this direction.

It is observed that the teaching staffs score on the "intermediate level" for "planning and decision making", "organizing and human resources", "team work", "communication" and "leadership" perceptions. Therefore, academic managers in Physical Education and Sport schools should use "planning and decision making", "organizing and human resources", "team work", "communication" and "leadership" more effectively within the managerial effectiveness subdivisions.

$>$ Since the level of organizational commitment at the schools of physical education and sports is generally "medium", the investigation of the relationship between the level of organizational commitment of instructors and the perceptions of managers' managerial effectiveness (planning and decision making, organizational and human resources management, team work, communication and leadership), levels will enable the SPES faculty to identify and resolve managerial problems and to strengthen them and consequently 
to increase their willingness to stay in the organization.

Because of the significant positive relationship between organizational commitment and managerial effectiveness subscales, academic managers should be aware of this relationship and effectively to use management functions while improving organizational commitment in SPESs. In this direction, various trainings should be held for academic administrators on the relation between organizational commitment and managerial effectiveness.

In line with our studies, with the studies to be carried out at different times, by comparing the current situation and using the findings from the results of this research, a contribution will be made to the academic development in a significant way by shedding light on the practices that increase the level of commitment of the teaching staff to their organizations. The applications that will eventually be performed will improve the quality of education by improving the attitudes of the instructors towards the institutions in a positive way.

In-depth examination of the managerial effectiveness dimensions of the instructors, who act as administrators in the schools of Physical Education and Sports in particular, to investigate the managerial effectiveness of the managers in order to improve their proficiency levels; more comprehensive results can be obtained with studies to be carried out by relating to issues such as organizational climate, organizational culture, exhaustion, job satisfaction, job performance, total quality, organizational trust.

\section{REFERENCES}

1. Al A. Investigating the managerial competency level of the principals at foreign languages departments of the universities and the level of commitment to the organization of the instructors of English. Unpublished Master's Thesis, Kocaeli University Institute of Social Sciences, 2007.

2. Allen NJ, Meyer JP. The measurement and antecedents of affective, continuance and normative commitment to the organization. Journal of Occupational Psychology, 1990; 63: $18-21$.

3. Aras M. Organizational commitment: An application on academic staff in GÖÜ, Unpublished Master's Thesis, Gaziosmanpaşa University Institute of Social Sciences, 2010.

4. Aslan A. The efficiency of the principals who were appointed by entering exam and the ones who were appointed without an exam according to administrator and teacher views. Unpublished Master's Thesis, Marmara University Institute of Educational Sciences, 2005.
5. Bakan İ, Büyükbeşe T, Bedestenci HÇ. Örgüt Kültürü: Teorik ve Ampirik Yaklaşım. Bursa: Aktüel Yayıncılık, 2004.

6. Batmunkh M. The relationship of leadership styles between organizational commitment and organizational silence and a research. Unpublished Master's Thesis, Marmara University Institute of Educational Sciences, 2011.

7. Battal N, Sahan $\mathrm{H}$. The evaluation of the administrators training organized at Necatibey faculty of education. Balikesir University Journal of Social Sciences Institute, 2002; 5(7): 2233.

8. Bekrek KGA. Study on the relationship between managerial influence tactics and organizational commitment with the moderating role of androgynous leadership. Unpublished Doctoral's Thesis, Yeditepe University Institute of Social Sciences, 2011.

9. Benkhoff B. Ignoring commitment is costly: New approaches establish the missing link between commitment and performance, Human Relations, 1997; 50: 701-726.

10. Büyüköztürk Ş. Sosyal Bilimler İçin Veri Analizi El Kitabı. 7. Baskı, Ankara: Pegem Yayıncılık, 2007.

11. Bozkurt Ö, Yurt İ. A Study to Determine the Organizational Commitment Level of the Academicians. Yönetim Bilimleri Dergisi, 2013; 11(22): 121-139.

12. Cook MD. Exploring the Impact of Management Functions on Indigeneous Policy. Unpublished Doctoral's Thesis, NorthCentral University, 2008.

13. Çerçi S. Impact of work values on organizational commitment and job performance: A study at Osmaniye Korkut Ata University. Master's Thesis, Osmaniye Korkut Ata University Institute of Social Sciences, 2013.

14. Çubukçu K, Tarakçıŏlu S. The relation between organizational trust and organizational commitment: A study on teachers of hotel management and tourism vocational high schools. Journal of Business Research, 2010; 2(4): 57-78.

15. Drew G, Bensley L. Managerial effectiveness for a new millennium in the global higher education sector. Higher Education in Europe, 2001; 26(1): 61-68.

16. Doğan V, Ozkara BY. The role of online brand trust on the image of online brands. Journal of Internet Applications and Management, 2013; 4(2): 5-20.

17. Doğrul MA. The relationship between organizational commitment and organizational citizenship behavior: A research on employees for Afyon Vocational School. Unpublished Master's Thesis, Afyon Kocatepe University Institute of Social Sciences, 2013.

18. Gürdoğan A. The effects of leadership behaviours of academicians who are at manager position in tourism departments of universities offering the undergraduate on organizational commitment of employees. Unpublished Doctoral's Thesis, Adnan Menderes University Institute of Social Sciences, 2010.

19. Günal SÖ. Management problems of higher education. Unpublished Doctoral's Thesis, Dokuz Eylül University Institute of Educational Sciences, 2006.

20. Goetsch D. Effective Leadership. Ten Steps for Technical Professions. New Jersey: Pearson Education, Prentice Hall, 2005. 
21. Ira N. Organizational culture (Dokuz Eylül Univercity sample). Unpublished Master's Thesis, Dokuz Eylül University Institute of Educational Sciences, 2004.

22. İra N. Organizational culture and managerial effectiveness in faculties of education. Unpublished Doctoral's Thesis, Dokuz Eylül University Institute of Educational Sciences, 2011.

23. İra N, Şahin S. Adaption of managerial effectiveness scale to Turkish. Buca Faculty of Education Journal, 2010; 28: 16-29.

24. Kalfa M, Karaman M, Tufan D. Organizational Commitment of People Working For Turkish Sports Management Organizations In Terms of Some Variables. European Scientific Journal, 2016; 12(2): 159-169.

25. Karslı MD. Yönetsel Etkililik. 2. baskı, Ankara: Pegem A Yayıncllık Tic. Ltd. Ş. 2004

26. Kaya A, Balay R.,Tinaz S. The Relationship between Managerial Effectiveness and Organizational Commitment Perceptions of Teachers and Principals. Ahi Evran University Journal of Kırşehir Education Faculty (KEFAD), 2014; 15(2): 79-97.

27. Kowalski TJ. Contemporary School Administration. New York: Pearson Education Inc. 2003.

28. Kurtbas D. Organizational commitment to the relationship between psychological violence scholars are exposed to public and the research foundation universities. Unpublished Master's Thesis, Gazi University Institute of Educational Sciences, 2011.

29. Meyer JP, Allen NJ. A Three-Component Conceptualization of Organizational Commitment. Human Resource Management Review, 1991; 1(1): 61-89.

30. Meyer JP, Allen NJ. Commitment in the Workplace, Theory, Research and Application. London: Sage Publications, 1997.

31. Mowday RT, Porter LW, Steers RM. Employee-Organization Linkages, the Psychology of Commitment. Absenteeism and Turnover, New York: Academic Press Inc, 1982.
32. Murry J. Development of Assessment Criteria to Determine the Managrial Effectiveness of Comunnity and Technical College Administrators. Unpublished Doctoral's Thesis, University of Arkansas, 1993.

33. Peterson WM, Blabkburn R. Faculty effectiveness: Meeting institutional needs and expectations. The Review of Higher Education, 1985; 9(1): 21-24.

34. Student Selection and Placement System (SSPS) Available: http://www.osym.gov.tr/BelgeGoster.aspx?F6E10F8892433CF F1A9547B61DAFFE2A185C4781D0FBC79E. Accessed February 27, 2013, 2011.

35. Turan S, Karadağ E, Bektaş F. Relationship between Learning Organization and Organizational Commitment in a University Structure. Educational Administration: Theory and Practice, 2011; 17(4); 627-638.

36. Usta ME. The effects of school administrators? Positivist or chaos management styles on commitment levels of their own and the teachers. Unpublished Doctoral's Thesis, Firat University Institute of Educational Sciences, 2013.

37. Wasti SA. Örgütsel Bağlılığı Belirleyen Evrensel ve kültürel Etmenler: Türk Kültürüne Bir Bakış, In: Ayçan Z. Türkiye'de Yönetim, Liderlik ve İnsan Kaynakları Uygulamaları, Ankara: Türk Psikologlar Derneği Yayınları. 2000.

38. Yaşbay $\mathrm{H}$. The relationship between authentic leadership and organizational commitment. Unpublished Master's Thesis, Dokuz Eylül University Institute of Social Sciences, 2011.

39. Yukl G. How leaders influence organizational effectivness. The Leadership Quarterly, 2008; 19: 708-722.

40. Yükseköğretim Kurulu (Council of Higher Education) (YÖK). The Turkish Higher Education System, retrieved March 2, 2013, from http://www.yok.gov.tr/english/edusys.html. 2007. 